\title{
PROPOSTA DE METODIZAÇÃO DA LINFADENECTOMIA MEDIASTINAL NA CIRURGIA DO CÂNCER DE PULMÃO
}

\author{
METHODIZATION FOR MEDIASTINAL LIMPHADENECTOMY IN LUNG \\ CANCER RESECTION
}

\author{
Vitório Moscon Puntel, TCBC- RJ ${ }^{1}$ \\ Rui Haddad, TCBC-RJ ${ }^{2}$
}

\begin{abstract}
RESUMO: Objetivo: Estabelecer uma padronização anatômica da linfadenectomia mediastinal como complementação à cirurgia do câncer de pulmão. Método: 1 - Foram enviados para vinte e dois cirurgiões torácicos brasileiros, questionários sobre linfadenectomia mediastinal. 2 - Realizou-se extensa revisão bibliográfica sobre a anatomia dos linfáticos do mediastino e descrições das técnicas de dissecação linfática mediastinal. 3 - Procedeu-se à dissecação do mediastino em cinco cadáveres não formolizados.4 - Estabelecido os limites anatômicos de cada loja linfonodal foram realizadas vinte e sete fotografias de cada uma das referidas lojas antes e após a dissecação. Resultados: Não houve consenso entre os cirurgiões que responderam ao questionário quanto a realização ou não e quanto à forma de realizar a linfadenectomia do mediastino na cirurgia do câncer pulmonar, significando que a técnica merece uma metodização. Movidos por esta necessidade e baseados na análise dos itens 2, 3 e 4 acima relacionados, propusemos uma metodização da linfadenectomia mediastinal de forma objetiva, definindo claramente os limites anatômicos de cada loja ganglionar no mediastino direito e esquerdo e especificando aquelas a serem abordadas de acordo com o sítio primário da lesão no lobo pulmonar. Conclusão: É possível definir claramente uma metodização técnica de fácil execução da linfadenectomia mediastinal, baseado em critérios anatômicos.
\end{abstract}

Descritores: Pulmão; Neoplasias pulmonares; Linfonodos; Excisão de Linfonodo; Cirurgia; Métodos.

\section{INTRODUÇÃO}

A partir da adoção da classificação TNM por Denoix ${ }^{1}$ em 1952 estabeleceu-se de forma lógica, clara e uniforme o estadiamento do câncer pulmonar não pequenas células. Este estadiamento adotado mundialmente em 1986 e revisado em 1997 é fator essencial para definir tipo de tratamento, incluindo indicação de cirurgia e a necessidade ou não de tratamento adjuvante, e estabelecer o real prognóstico da doença ${ }^{2,3}$. A linfadenectomia me- diastinal é parte essencial deste estadiamento por definir o nível de comprometimento dos linfonodos desta região, a chamada doença $\mathrm{N} 2$, associada a um pior prognóstico do câncer. Persistem no entanto controvérsias sobre o real impacto da linfadenectomia mediastinal na sobrevida dos pacientes portadores de doença N2.

Alguns autores ${ }^{4-10}$ preconizam sua utilização rotineira visando não só um completo estadiamento, como também uma melhora na sobrevida. Outros autores não realizam a linfadenectomia, por

1. Aluno da Pós-Graduação (nível doutorado) em Cirurgia torácica pela Faculdade de Medicina da UFRJ; Responsável pelo setor de Cirurgia Torácica do Hospital São João Batista - Escola de Ciências Médicas - Centro Universitário de Volta Redonda, RJ.

2. Professor Adjunto do Departamento de Cirurgia da Faculdade de Medicina da UFRJ; Chefe da Divisão de Cirurgia Torácica do Instituto de Doenças do Tórax da UFRJ.

Recebido em: 03/05/2002

Aceito para publicação em: 17/09/2002

Trabalho do curso de pós-graduação em medicina (nível mestrado), área de concentração: Cirurgia Geral - Setor Torácico - Departamento de Cirurgia da Faculdade de Medicina da UFRJ e da Divisão de Cirurgia Torácica do Instituto de Doenças do Tórax da UFRJ. 
entenderem que a mesma não altera a sobrevida e pode aumentar a morbidade do ato cirúrgico ${ }^{11-14}$.

Para estudar se haveria necessidade de metodizar a linfadenectomia mediastinal, no tratamento cirúrgico do carcinoma pulmonar, foram enviados e respondidos por vinte e dois cirurgiões torácicos brasileiros, um questionário sobre linfadenectomia mediastinal .Pela avaliação das respostas concluímos não haver um consenso quanto a fazer ou não a linfadenectomia mediastinal e também, entre os que a realizam, quanto à forma de fazê-la. O objetivo deste trabalho, desta forma, foi propor uma metodização da linfadenectomia mediastinal baseada em critérios atuais de disseminação do câncer e em critérios anatômicos locais, definindo áreas a serem dissecadas de acordo com a localização do tumor primário.

\section{MÉTODO}

Após análise das respostas ao questionário enviado (Quadro1), extensa revisão bibliográfica a respeito da anatomia das vias de conexão dos linfáticos do pulmão e do mediastino ${ }^{15-18}$ e avaliação das técnicas de linfadenectomia mediastinal referidas na literatura ${ }^{4,7,8,19-21}$, realizou-se a dissecação de cinco cadáveres não formolizados, faixa etária de 31 à 60 anos, sendo apenas um do sexo feminino. Nenhum dos óbitos esteve relacionado com doença primária pulmonar. A abordagem se deu com o cadáver em decúbito dorsal com incisão mediana tóraco-adominal a partir da fúrcula esternal até o púbis com retirada do plastrão esternal. Foram abordados o mediastino direito e esquerdo de forma sequiencial, com dissecação e delimitação das lojas mediastinais e seus principais limites anatômicos. Um total de 27 fotografias foram realizadas mostrando individualmente cada loja mediastinal antes e após a dissecação identificando-se os principais reparos anatômicos. Exemplificamos com fotos do mediastino superior direito (Figuras 1 e 2) e da janela aorto-pulmonar (Figuras 3 e 4) antes e após a linfadenectomia.

Quadro 1 - Tabulação das informações colhidas no questionário enviado aos cirurgiões torácicos.

\begin{tabular}{|c|c|c|c|c|c|c|}
\hline Incisão: & $\begin{array}{c}\text { Póstero-lateral } \\
09\end{array}$ & $\begin{array}{c}\text { TAVA \# } \\
05\end{array}$ & \multicolumn{2}{|c|}{$\begin{array}{c}\text { Anterior } \\
01\end{array}$} & $\begin{array}{c}\text { Lateral } \\
03\end{array}$ & $\begin{array}{c}\text { não referiu } \\
04\end{array}$ \\
\hline \multirow{2}{*}{\multicolumn{3}{|c|}{ Faz Linfadenectomia radical: }} & \multicolumn{2}{|c|}{ SIM* } & $\mathrm{NÃO} * *$ & \\
\hline & & & \multicolumn{2}{|c|}{15} & 07 & \\
\hline \multirow{2}{*}{\multicolumn{2}{|c|}{ * Metodização empregada: }} & Naruke & Martini & Izibicki & Watanabe & Não referiu \\
\hline & & 07 & 04 & - & - & 04 \\
\hline \multirow{2}{*}{\multicolumn{2}{|c|}{$* *$}} & \multicolumn{2}{|c|}{ Apenas amostragem } & \multicolumn{3}{|c|}{ apenas ressecção pulmonar } \\
\hline & & \multicolumn{2}{|l|}{06} & \multicolumn{3}{|c|}{01} \\
\hline \multirow{2}{*}{\multicolumn{2}{|c|}{ Faz Linfadenectomia radical: }} & \multicolumn{2}{|c|}{ No início } & No fim & \multicolumn{2}{|c|}{ Sem preferência } \\
\hline & & \multicolumn{2}{|l|}{04} & 10 & \multicolumn{2}{|c|}{01} \\
\hline \multirow{2}{*}{\multicolumn{4}{|c|}{ Conhece algum trabalho nacional sobre o tema? }} & SIM & \multicolumn{2}{|c|}{ NÃO } \\
\hline & & & & 01 & \multicolumn{2}{|c|}{21} \\
\hline
\end{tabular}

\#TAVA - toracotomia axilar vertical ampla.

Vinte e dois cirurgiões torácicos de diferentes regiões do país responderam ao questionário. 

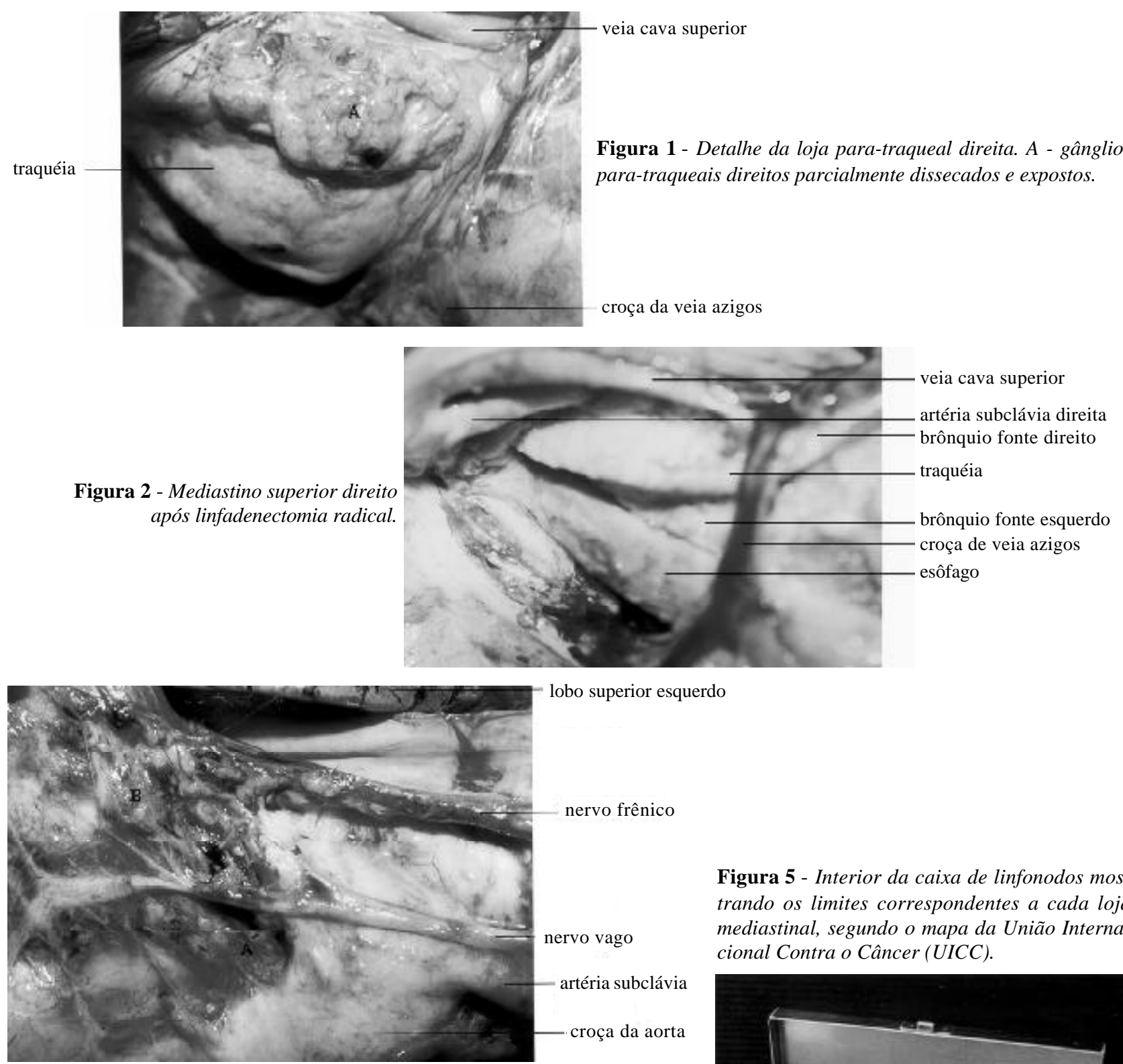

Figura 3 - Mediastino superior esquerdo: A - janela aortopulmonar; $B$ - gânglios entre os nervos frênico e vago.

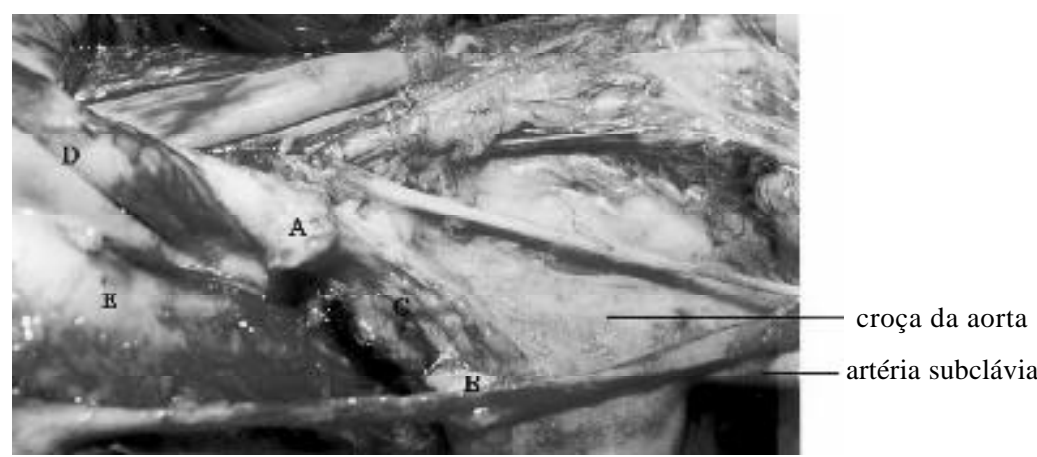

Figura 4 - Mediastino superior: dissecção da janela aorto-pulmonar: A, $B$ - ligamento arterioso seccionado; $C$ - gânglio da janela; $D$ - artéria pulmonar; $E$ - brônquio fonte esquerdo.
Figura 5 - Interior da caixa de linfonodos mostrando os limites correspondentes a cada loja mediastinal, segundo o mapa da União Internacional Contra o Câncer (UICC).

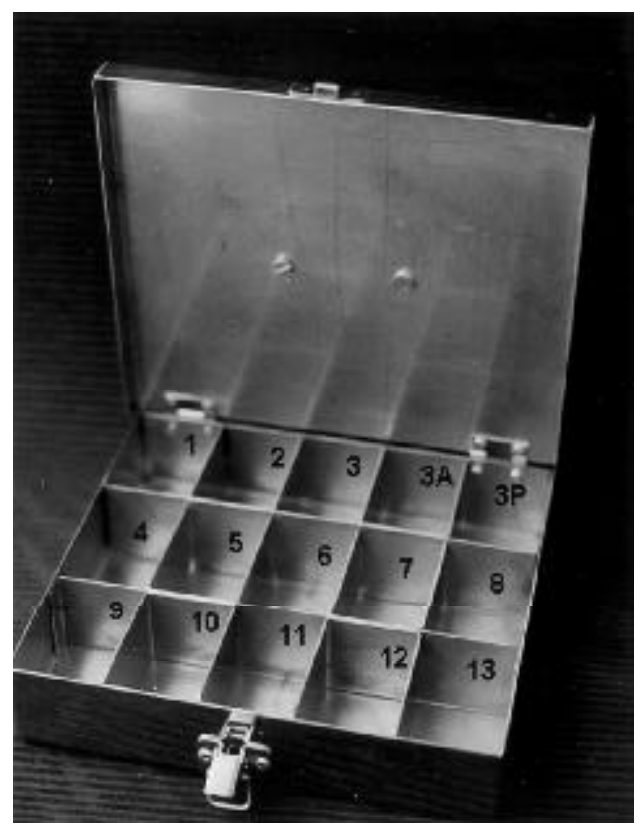




\section{RESULTADO}

Procedeu-se então a proposta de metodização da linfadenectomia mediastinal ${ }^{22}$. Acesso cirúrgico é realizado com o paciente em decúbito lateral e intubação seletiva, optando-se por toracotomia póstero-lateral clássica ou por toracotomia axilar vertical ampla com preservação muscular, abordando-se o quinto espaço intercostal. A critério do cirurgião, pode-se realizar ou não costectomia. Fazemos a liberação de rotina do ligamento triangular pulmonar e inventário de toda a cavidade pleural. A abordagem das lojas mediastinais para dissecção dos linfonodos é feita previamente à ressecção pulmonar, nos casos de tumores periféricos sem comprometimento hilar. Já nos casos de tumores centrais com comprometimento de estruturas do hilo pulmonar a linfadenectomia é feita após a ressecção pulmonar. Ao término da dissecção de cada loja mediastinal, os linfonodos são colocados em uma caixa contendo subdivisões (Figura 5) sendo que cada divisão está rotulada com o número de uma área linfonodal, constante do mapa da União Internacional Contra o Câncer (UICC), encaminhada para estudo histopatológico, após estudo per-operatório de congelação.

\section{Metodização}

Nas lesões do lobo superior direito e médio, indica-se a dissecção dos linfonodos da região mediastinal superior direita:

A) ligadura da croça da veia ázigos, junto à coluna vertebral e junto à sua desembocadura na veia cava superior.

B) dissecção de toda a gordura mediastinal anterior ao nervo frênico tendo como limite mais anterior os vasos torácicos internos.

C) timectomia parcial (lobo direito), liberando toda a gordura até expor a veia cava superior, o tronco venoso inominado, o tronco arterial braquiocefálico junto à sua bifurcação até o nível artéria subclávia direita, idealmente com identificação do nervo laríngeo recorrente direito, ponto mais alto da dissecção.

D) disseca-se agora em sentindo crâniocaudal ressecando sistematicamente a gordura e os gânglios das faces anterior, lateral e posterior da traquéia, expondo o esôfago superior, toda a face lateral da traquéia e veia cava superior (neste ponto pequenas veias que drenam para a cava devem ser ligadas ou mais facilmente clipadas), de forma que seja possível visualizar a face direita do arco aórtico. Ainda em sentindo caudal, dissecam-se em conjunto os gânglios da croça da veia ázigos e das faces superior, anterior e posterior da junção tráqueo-brônquica e brônquio fonte direito. Cada conjunto de gânglios e gordura de cada loja mediastinal deve ser colocado na caixa de linfonodos em seu compartimento específico.

Ao final desta dissecção deve ser possível identificar com clareza as seguintes estruturas: todo o pericárdio anterior ao nervo frênico livre de gordura tímica; todo a borda lateral e anterior da veia cava superior e sua junção com a veia braquiocefálica; a emergência da artéria subclávia direita e o nervo laríngeo recorrente direito; toda a face lateral da traquéia e esôfago até o nível da croça da veia ázigos; o bordo superior da artéria pulmonar direita e a face direita da aorta ascendente entre a veia cava superior e a traquéia.

Nas lesões do lobo inferior direito e médio, indica-se a dissecção dos linfonodos da região mediastinal inferior direita:

A) dissecção e limpeza da região subcarinal onde deverão ser encontrados ou um grande gânglio ou um conjunto deles em conexão com os linfonodos traqueobrônquicos inferiores direito e esquerdo, que devem ser retirados em conjunto.

B) dissecção em sentindo cranial à dissecção dos linfonodos do ligamento triangular pulmonar, previamente liberado, ou da gordura mediastinal, até a veia pulmonar inferior e a seguir, a dissecção do esôfago inferior, liberando toda a gordura adjacente e os possíveis gânglios, de forma a expor a face lateral direita deste órgão.

Ao final desta dissecção, deverá ser possível identificar com clareza as seguintes estruturas anatômicas: carina principal e face inferior do brônquio-fonte direito e esquerdo; veia pulmonar inferior direita, pericárdio anterior ao nervo frênico livre de gordura; toda a face lateral direita do esôfago até o diafragma; veia ázigos junto ao esôfago.

Nas lesões do lobo superior esquerdo, indica-se a dissecção dos linfonodos da região mediastinal superior esquerda:

A) identificação e, se necessário, reparo dos nervos frênico e vago, realizando-se a retirada de todos os linfonodos e gordura encontrados posteriormente ao nervo vago, entre este e o nervo frênico e anteriormente a este. Limpeza dos gânglios da veia pulmonar superior. 
B) retirada de toda a gordura, anterior ao nervo frênico, inclusive a tímica. Exposição da veia braquiocefálica esquerda no seu cruzamento com a traquéia. A partir deste ponto, expõem-se a artéria carótida comum esquerda e a artéria subclávia esquerda, desde sua emergência na croça da aorta com ligadura e secção da veia hemiázigos até o ponto mais alto possível do tórax, retirando todos os linfonodos e gordura situados entre estes dois vasos, anteriormente à carótida comum e posterior à artéria subclávia.

C) dissecção da janela aorto-pulmonar com secção do ligamento arterioso, identificação do nervo laríngeo recorrente, o que permite uma certa mobilização da croça da aorta com ressecção dos linfonodos traqueobrônquicos situados nesta loja. Não realizamos mobilização da croça da aorta com ligadura e secção de vasos intercostais nem esternotomia mediana para acessar os linfonodos pré-traqueais.

Ao final desta dissecção, deverá ser possível identificar com clareza as seguintes estruturas anatômicas: croça da aorta, carótida comum e subclávia esquerdas até o ponto mais alto no ápice do tórax; veia braquiocefálica esquerda; nervos frênico, vago e laríngeo recorrente na janela aorto-pulmonar que deve estar vazia, todo o pericárdio anterior ao nervo frênico livre de gordura; face lateral do esôfago superior, posterior à artéria subclávia esquerda.

Nas lesões do lobo inferior esquerdo, indica-se a dissecção dos linfonodos da região mediastinal inferior esquerda: pulmão.

A) liberação do ligamento triangular do

B) dissecção dos linfonodos deste ligamento até expor por completo a veia pulmonar inferior; exposição da região subcarinal esquerda que é dissecada por completo expondo-se o brônquio-fonte esquerdo, a bifurcação traqueal e o brônquio-fonte direito.

C) liberação de toda a gordura e linfonodos para-esofageanos, deixando exposto por completo todo o esôfago inferior e aorta descendente além do pericárdio posterior e anterior ao nervo frênico.

Ao final desta dissecção deverá ser possível identificar com clareza as seguintes estruturas anatômicas: bifurcação brônquica, brônquio-fonte direito e esquerdo em suas faces inferiores; veia pulmonar inferior em toda a sua extensão; esôfago em sua porção inferior, desde a carina principal até o diafragma; aorta descendente até o seu limite com os corpos vertebrais posteriormente; pericárdio posterior e anterior ao nervo frênico.
Como parte desta metodização, estabeleceuse que:

\section{Nas lesões do lobo superior direito:}

1) linfadenectomia radical do mediastino superior direito, seguida da ressecção dos linfonodos subcarinais, que são enviados para exame de congelação, e caso estejam comprometidos, complementa-se com a linfadenectomia radical do mediastino inferior direito.

2) congelação dos linfonodos subcarinais negativa, faz-se apenas a amostragem de linfonodos do ligamento triangular pulmonar.

\section{Nas les̃̃es do lobo médio:}

1) bilobectomia incluindo o lobo inferior quando o "sump" entre o lobo médio e o inferior estiver comprometido, seguida de linfadenectomia radical do mediastino inferior.

2) congelação dos linfonodos subcarinais positiva, complementa-se com linfadenectomia também do mediastino superior.

3) quando o "sump" entre o lobo médio e o superior estiver comprometido, associa-se a lobectomia superior, seguida da linfadenectomia do mediastino superior e subcarinal.

4) gânglios subcarinais positivos, complementa-se com a dissecção do mediastino inferior.

5) em ambas as situações, caso o exame de congelação não mostre comprometimento subcarinal, realiza-se a amostragem de pelo menos um gânglio no mediastino superior e inferior, respectivamente.

\section{Nas lesões do lobo inferior direito:}

1) linfadenectomia radical do mediastino inferior direito, com congelação dos linfonodos subcarinais.

2) se estes estiverem comprometidos, também complementa-se com a extensão da linfadenectomia para o mediastino superior direito.

3) ao contrário, faz-se a amostragem de pelo menos um gânglio de cada loja do mediastino superior.

Nas lesões do lobo superior esquerdo:

1) linfadenectomia radical do mediastino superior esquerdo, com a linfadenectomia dos gânglios subcarinais de rotina.

2) caso estes estejam comprometidos ao exame de congelação, estende-se a linfadenectomia para todo o mediastino inferior e gânglios do brônquio fonte direito, em continuidade com os subcarinais. 
3) caso negativo, faz-se a amostragem de pelo menos um gânglio de cada loja do mediastino inferior.

Nas lesões do lobo inferior esquerdo:

1) linfadenectomia radical do mediastino inferior esquerdo com congelação dos linfonodos subcarinais.

2) se estes estiverem positivos, procede-se à extensão da linfadenectomia para o mediastino superior esquerdo, principalmente janela aorto-pulmonar.

3) se os gânglios subcarinais estiverem negativos, faz-se a amostragem de pelo menos um gânglio de cada loja acessível do mediastino superior esquerdo.

Nos casos em que foi necessário uma pneumonectomia, realiza-se, de rotina, à linfadenectomia radical de todas as lojas mediastinais, sem exceção.

\section{DISCUSSÃO}

A utilização da linfadenectomia mediastinal de rotina na cirurgia do câncer pulmonar continua sendo matéria controversa. Existem autores ${ }^{4-10}$ que a utilizam de forma rotineira pois acreditam que a mesma influencia positivamente a sobrevida. Keller ${ }^{23} \mathrm{em}$ trabalho prospectivo e randomizado demonstrou uma melhor sobrevida em pacientes portadores de câncer em lobo superior direito submetidos a linfadenectomia radical mediastinal se comparados com aqueles submetidos apenas a amostragem. Este dado poderia estar relacionado a uma condição anatômica mais favorável para o esvaziamento completo do mediastino superior direito. Izbicki ${ }^{24}$ também em trabalho prospectivo e randomizado não pode demonstrar uma melhora na sobrevida dos pacientes submetidos a linfadenectomia mediastinal radical quando comparado com pacientes submetidos apenas a amostragem de linfonodos mediastinais, corroborando resultados de outros autores ${ }^{11-14}$. Izbicki 21 não observou aumento da morbi-mortalidade relacionada com à linfadenectomia mediastinal radical nem uma diferença significativa no estadiamento mediastinal se comparada a linfadenectomia com a amostragem de linfonodos. No entanto a detecção do envolvimento linfonodal mediastinal em múltiplas áreas foi significativamente aumentada pela linfadenectomia radical e isto influenciou na sobrevida ${ }^{25}$. Riquet ${ }^{17,18}$ em estudo anatômico concluiu ser necessária, como rotina, uma dissecção dos linfonodos mediastinais ipsilaterais durante a cirurgia do carcinoma pulmonar, mesmo quando não houver linfonodos intrapulmonares comprometidos, já que em 20 a $40 \%$ dos casos, existem canais linfáticos que drenam diretamente para os linfonodos mediastinais. Para ele, a anatomia explica a necessidade de uma linfadenectomia mediastinal como parte essencial do tratamento cirúrgico.

Concluímos ser possível definir claramente uma metodização técnica de fácil execução da linfadenectomia mediastinal, baseado em critérios anatômicos.

\begin{abstract}
Background: To establish an easily performing methodization for mediastinal limphadenectomy technique as a complement to lung cancer resection. Methods: Twenty-two standard questionnaire were sent to several thoracic surgeons from several parts of Brazil. We evaluated the literature about the techniques described for mediastinal limphadenectomy by the following authors: Naruke, Martini, Izibicki and Watanabe. A literature review on the anatomy of mediastinal and pulmonary lymphatics has been carried out. After that, five fresh corpses of adult individuals of both sexes were dissected, and we sougth for a definition of the mediastinal areas and anatomic limits, important for limphadenectomy, as well as an individualization of the several lymph node groupings of each area. Results: From the analysis of twenty-two answers to a standard questionnaire, we may conclude that there is a lack of technical methodization and a diversity of opinions on this issue. An easy performing methodization for mediastinal limphadenectomy technique was proposed. Conclusions: It's possible to establish an easily performing methodization for mediastinal limphadenectomy technique based in anatomical criteria.
\end{abstract}

Key Words: Lung; Lung neoplasms; Lymph nodes; Lymph node excision; Surgery; Methods. 


\section{BIBLIOGRAFIA:}

1. Naruke T, Tsuchiya R, Kondo H, et al. - Implications of staging in lung cancer. Chest, 1997, 112 (Suppl 4): S242-S248.

2. Mountain CF - A new international staging system for lung cancer. Chest, 1986, 89(Suppl 4): S225-S233.

3. Mountain CF, Dresler CM - Regional lymph node classification for lung cancer staging. Chest, 1997, 111(6): 1718-1723.

4. Martini N, Flehinger BJ - The role of surgery in N2 lung cancer. Surg Clin North Am, 1987, 67(5): 1037-1049.

5. Naruke T, Suemasu K, Ishikawa S - Lymph node mapping and curability at various levels of metastasis in resected lung cancer. J Thorac Cardivasc Surg, 1978, 76(6): 832-839.

6. Riquet M, Manac'h D, Daab M, et al. - Factors determining survival resected N2 lung cancer. Eur J Cardiothorac Surg, 1995, 9(6): 300-304.

7. Watanabe Y, Shimizu J, Tsubota M, et al. - Mediastinal spread of metastatic lymphnodes in bronchogenic carcinoma. Mediastinal nodal metastasis in lung cancer. Chest, 1990, 97(5): 1059-1065.

8. Watanabe Y, Shimizu J, Oda M, et al. - Improved survival in left non-small-cell N2 lung cancer after more extensive operative procedure. Thorac Cardiovasc Surg, 1991, 39(2): 39(2): 89-94.

9. De Lyen P, Schoonooghe P, Deneffe G, et al. - Surgery for non-small cell lung cancer with unsuspected metastasis to ipsilateral mediastinal or subcarinal nodes (N2 disease). Eur J Cardiothorac Surg, 1996, 10(8): 649-655.

10. Ishida T, Yano T, Kaneko S, et al. - Strategy for lymphadenectomy in lung cancer three centimeters or less in diameter. Ann Thorac Surg, 1990, 50(5): 708-713.

11. Sugi K, Nawata K, Fujita N, et al. - Systematic lymph node dissection for clinically diagnosed peripheral nonsmall cell lung cancer less than $2 \mathrm{~cm}$ in diameter. World J Surg, 1998, 22(3): 290-295.

12. Lewis RJ - Is radical lymphadenectomy a valid oncologic procedure. Eur J Cardiothorac Surg, 1999, 16 (suppl. 1): S11-S12.

13. Funatsu T. Matsubara Y, Ikeda S, et al. - Preoperative mediastinoscopic assessment of $\mathrm{N}$ factors and the need for mediastinal lymph node dissection in T1 lung cancer. J Thorac Cardiovasc Surg, 1994, 108(2): 321-328.

14. Robert J, Mathey P, Mermillod B, et al. - Surgical resection of primary lung cancer. A 13-year experience in Geneva. Ann Chir, 1997, 51(7): 682-688.
15. Rouviere H. Anatomie des lymphatiques de l'homme. Paris, Masson et Cie. 1932, pp. 168-189 e pp. 209 - 218.

16. Brock SR, Whytehead L - Radical pneumonectomy for bronchial carcinoma. Br J Surg, 1955, 43(1): 8-24.

17. Riquet M, Hidden G, Debesse B - Direct lymphatic drainage of lung segments to the mediastinal nodes. An anatomic study on 260 adults. J Thorac Cardiovasc Surg, 1989, 97(4): 623-632.

18. Riquet $\mathrm{M}$ - Anatomic basis of lymphatic spread from carcinoma of the lung to the mediastinum: surgical and prognostic implications. Surg Radiol Anat, 1993, 15(4): 271-277.

19. Naruke T - Mediastinal lymph node dissection. In: General Thoracic Surgery. Baltimore, Willians \& Wilkins, 1994, p. 469-480.

20. Martini N-Mediastinal lymph node dissection for lung cancer. The Memorial experience. Chest Surg Clin North Am, 1995, 5(2): 189-203.

21. Izbicki JR, Thetter O, Habekost M, et al. - Radical systematic mediastinal lymphadenectomy in non-small cell lung cancer: a randomized controlled trial. Br J Surg, 1994, 81(2): 229 - 235.

22. Puntel VM. Metodização da linfadenectomia mediastinal na cirurgia do câncer de pulmão. Dissertação (Mestrado em Cirurgia Geral - Setor Tórax). Rio de Janeiro. Universidade Federal do Rio de Janeiro, 2000, 147p.

23. Keller SM, Adak S, Wagner $\mathrm{H}$, et al. - Mediastinal lymph node dissection improves survival in patients with stages II and IIIa non-small cell lung cancer. Eastern Cooperative Oncology Group. Ann Thorac Surg, 2000, 70(2): 358-365.

24. Izbicki JR, Passlick B, Pantel K, et al. - Effectiveness of radical systematic mediastinal lymphadenectomy in patients with resectable non-small cell lung cancer: results of a prospective randomized trial. Ann Surg, 1998, 227(1): 138-144.

25. Izbicki JR, Passlick B, Karg O, et al. Impact of radical systematic mediastinal lymphadenectomy on tumor staging in lung cancer. Ann Thorac Surg, 1995, 59(1): 209-214.

Endereço para correspondência:

Dr. Vitório Moscon Puntel

Rua Santa Júlia, 21

Bairro Niterói - Volta Redonda - RJ

CEP: 27283-460

E-mail: vpuntel@uol.com.br 